\title{
Surgical Treatment of Lutembacher Syndrome with a Huge Right Atrium: A Case Report
}

\author{
Maodong Yang, ${ }^{1,2}$ Li Zhang, ${ }^{1,2}$ Han Tang, ${ }^{1,2}$ Linsong Liu, ${ }^{1,2}$ Jian $\mathrm{Wu}^{1,2}$ \\ ${ }^{1}$ Department of Cardiovascular Surgery, Yan'an Affiliated Hospital of Kunming Medical University, Kunming, China \\ ${ }^{2}$ Central Laboratory, Yan'an Affiliated Hospital of Kunming Medical University, Kunming, China
}

\section{ABSTRACT}

Background: Lutembacher's syndrome (LS) is a rare cardiovascular anomaly that is defined as any combination of congenital or iatrogenic atrial septal defect (ASD) with congenital or acquired mitral stenosis (MS). The clinical features and hemodynamic effects of LS depend on the balance between ASD and MS.

Case Report: In this case report, we describe a rare case of LS with a huge right atrium in a 39-year-old male patient who was admitted to the hospital with worsening fatigue and breathlessness on exertion. Clinical examination revealed central cyanosis, raised jugular venous pressure bilaterally, clear breath sounds bilaterally with no dry and wet rales, hyperdynamic apex beat, and dull heart sounds. His vital signs on admission included blood pressure of 90/60 mmHg, irregular pulse of 76 beats/min, and oxygen saturation of 90.4\%. Echocardiography revealed moderate to severe MS with ASD (ostium secundum). The patient's condition deteriorated after initial medical management, and he underwent open heart surgery for mitral valve replacement, ASD repair, tricuspid annuloplasty, and right atrial volume reduction.

Conclusions: This case report describes the successful surgical management of this rare condition.

\section{INTRODUCTION}

Lutembacher syndrome (LS) is an extremely rare clinical condition first reported in 1916 by the French physician Rene Lutembacher, who described a 61-year-old woman with atrial septal defect (ASD) and mitral stenosis (MS) [Mahajan 2020]. LS is defined as any combination of congenital or iatrogenic atrial ASD with congenital or acquired MS [Alam 2019]. The incidence of this disease is extremely low, affecting approximately $0.6 \%$ to $0.7 \%$ of individuals with MS. Congenital MS combined with congenital ASD is rare and accounts for only $0.6 \%$ of all cases of congenital heart disease [Mahajan 2020].

Received fanuary 27, 2021; received in revised form March 2, 2021; accepted March 4, 2021.

Correspondence: Fian Wu, Yan'an Affiliated Hospital of Kunming Medical University, Kunming, 650051, China; 15559720468 (e-mail: wujiankmmu@163.com).
The treatment of LS mainly includes open thoracic surgery, mitral valve (MV) replacement or repair, and atrial septal repair. Percutaneous balloon valvuloplasty of the MV with transcatheter ASD closure is sometimes used as an effective alternative to thoracotomy.

\section{CASE REPORT}

A 39-year-old male patient was admitted to the hospital with a 5-year history of fatigue and exertional dyspnea, which had worsened over the preceding year. These symptoms were also associated with palpitations and intermittent abdominal distension during physical activity. There was no history of rheumatic fever. His vital signs on admission included blood pressure of 90/60 mmHg $(1 \mathrm{mmHg}=0.133 \mathrm{kPa})$, irregular pulse of 76 beats/min, and oxygen saturation of $90.4 \%$. On examination, he had cyanotic lips, raised jugular venous pressure bilaterally, clear breath sounds bilaterally with no dry and wet rales, a hyperdynamic apex beat, and heart with widened boundary on both sides. The first heart sound was loud and the second heart sound was fixed and split. A grade III/VI diastolic murmur was auscultated in the mitral area, and a grade III/VI systolic murmur was auscultated in the pulmonary valve area. Moreover, there was no tenderness in the whole abdomen, and the enlarged liver could be touched under the right rib. The spleen was not palpable; and the lower limbs were slightly edematous.

Laboratory examination showed the following results: red blood cell count, $4.96 \times 10^{12} / \mathrm{L}$; white blood cell count, 4.91 $\times 10^{9} / \mathrm{L}$; carbon dioxide partial pressure, $32.0 \mathrm{mmHg}$; oxygen partial pressure, $59.6 \mathrm{mmHg}$; bicarbonate, $21.7 \mathrm{mmol} / \mathrm{L}$; cardiac troponin, $0.02 \mu \mathrm{g} / \mathrm{mL}$; N-terminal pro-B-type natriuretic peptide, $2066 \mathrm{ng} / \mathrm{L}$; antistreptolysin $\mathrm{O}$ titer, $43.40 \mathrm{IU} /$ $\mathrm{mL}$; hypersensitivity C-reactive protein, $3.21 \mathrm{mg} / \mathrm{L}$; and erythrocyte sedimentation rate, $9 \mathrm{~mm} / \mathrm{h}$.

Atrial fibrillation was confirmed on electrocardiography. A chest radiograph showed features of severe pulmonary hypertension with a cardiothoracic ratio (CR) of 0.73 , suggesting the presence of heart disease characterized by a left-to-right shunt. Echocardiography revealed (1) a huge right atrium (RA) (Figure 1) with significantly enlarged inner diameter of the right ventricle (RV) and left atrium (LA); (2) an enlarged left ventricle (LV); (3) a pulmonary aneurysm-like expansion (pulmonary artery systolic pressure $100 \mathrm{mmHg}$ ); (4) ASD (ostium secundum) measuring approximately $2.3 \mathrm{~cm}$ with a bidirectional low-velocity shunt; (5) MV disease (moderate to 
severe MV stenosis with mild insufficiency; $M V$ area $0.9 \mathrm{~cm} 2$ ) and severe tricuspid regurgitation with a thickened tricuspid valve (TV), annulus diameter $5.5 \mathrm{~cm}$; (6) abnormal ventricular septal movement with no evidence of thickening of the ventricular septum and posterior wall of the LV; (7) mild aortic valve insufficiency; (8) impaired LA contraction with reduced diastolic function; and (9) a small-volume pericardial effusion. Preoperative heart size is shown in Table 1. Left ventricular ejection fraction was $45 \%$, and total lung resistance of cardiac catheterization was 6.9 Woods units.

The differential diagnoses on admission were congenital heart disease, ASD, MV stenosis and insufficiency, TV insufficiency, pulmonary hypertension, atrial fibrillation, and heart failure (New York Heart Association [NYHA] functional class III). The patient was started on treatment with oxygen and diuretics. On day 6 of admission, he developed chest tightness and shortness of breath, and clinical examination revealed low blood pressure $(90 / 60 \mathrm{mmHg})$, cold extremities, and wet rales in both lungs. The patient was treated with a continuous infusion of dopamine $(3.8 \mu \mathrm{g} / \mathrm{kg} / \mathrm{min})$ to promote diuresis. The patient's case was discussed at a multidisciplinary team meeting, and he provided his consent for MV replacement, ASD repair, tricuspid annuloplasty, and right atrial volume reduction.

Hypothermic cardiopulmonary bypass surgery was performed. Intraoperatively, the heart was shown to be enlarged, including the RA, RV (Figure 2), and pulmonary artery, with an aorta:pulmonary artery ratio of approximately $1: 2$. Cardioplegia was administered to induce cardiac arrest. The RA was opened to visualize the ASD (secondary hole, central type, close to the upper cavity, and approximately $2 \times 2 \mathrm{~cm}$ ); after trimming the weak tissue, the defect was about $4 \times 2 \mathrm{~cm}$, and no mural thrombus in the LA or left atrial appendage was noted.

Exploration revealed MV disease with severe stenosis, MV insufficiency, thickened leaflets, calcification, and fusion of the chordae and papillary muscles. The diseased MV was removed, retaining part of the posterior valve, and was replaced with a St. Jude $(25-\mathrm{mm})$ mechanical valve with interrupted and continuous suturing. The TV valve annulus was significantly enlarged, and there was regurgitant flow through the TV. The MC3 (4900T30) annulus was intermittently sutured to perform tricuspid annuloplasty. No obvious regurgitation was noted after the water injection test. Thereafter, the RA incision was closed, the RA volume was reduced (Figure 3), and the heart automatically resumed beating. Intraoperative extracorporeal circulation time was $150 \mathrm{~min}$, aortic occlusion time was $80 \mathrm{~min}$, perfusion was performed twice, and the surgery lasted $5 \mathrm{~h}$.

Postoperatively, the patient was started on a combined infusion of dopamine $(7.0 \mu \mathrm{g} / \mathrm{kg} / \mathrm{min})$, epinephrine $(0.01 \mu \mathrm{g} / \mathrm{kg} /$ $\mathrm{min})$, and nitroglycerin $(0.1 \mu \mathrm{g} / \mathrm{kg} / \mathrm{min})$. Central venous pressure fluctuated between 5 and $8 \mathrm{mmHg}$. The patient was extubated 3 days after the surgery and was moved to the general ward, where he received alprostadil (micro-pumped), to lower pulmonary artery pressure, and warfarin anticoagulant therapy. He recovered and was discharged on day 12 after surgery.

Histological examination revealed valvular fibrous hyperplasia with hyaline degeneration, mucus-like deformation, and calcification. A chest radiograph repeated 10 days postoperatively showed a significant reduction in CR (0.62). At the 3-month follow-up, his symptoms had improved significantly (NYHA class II). A repeat echocardiogram revealed an increase in cardiac diameter, with no thickening of the ventricular septum and posterior wall of the $\mathrm{LV}$, and abnormal ventricular septal movement. The artificial valve leaflets opened and closed flexibly, and the annulus and the surrounding tissues moved in harmony. There was also reduced ventricular septal movement with mild insufficiency of all 3 aortic cusps. Spectral and color Doppler ultrasound blood flow imaging findings were as follows: red main blood flow signal in the LV inflow tract during diastole (peak value $187 \mathrm{~cm} / \mathrm{s}$, peak pressure difference $13 \mathrm{mmHg}$ ) and no obvious blood flow signal at the atrial level; the area of the MV orifice was $1.9 \mathrm{~cm}^{2}$ as measured by the Doppler pressure half-time method; and there was regurgitant blood flow signal in the aortic valve and TV. The postoperative heart size is shown in Table 1 .

\section{DISCUSSION}

LS is a rare heart malformation characterized by any combination of congenital or iatrogenic ASD and congenital or acquired MS. The clinical features and hemodynamic effects

Table 1. Cardiac Structure and Function before and after Surgery*

\begin{tabular}{|c|c|c|c|c|c|c|c|c|}
\hline Before surgery & 0.73 & $100 \times 82$ & 57 & 51 & 43 & 45 & $\begin{array}{l}\text { Moderate to severe stenosis } \\
\text { with mild insufficiency }\end{array}$ & Severe insufficiency \\
\hline 1 month after surgery & 0.62 & $71 \times 51$ & 31 & 42 & 50 & 45 & $\begin{array}{l}\text { Normal mechanical mitral } \\
\text { valve function }\end{array}$ & Mild insufficiency \\
\hline 1 year after surgery & 0.55 & $60 \times 59$ & 34 & 42 & 52 & 55 & $\begin{array}{c}\text { Normal mechanical mitral } \\
\text { valve function }\end{array}$ & Mild insufficiency \\
\hline
\end{tabular}

*LVEF indicates left ventricular ejection fraction. 


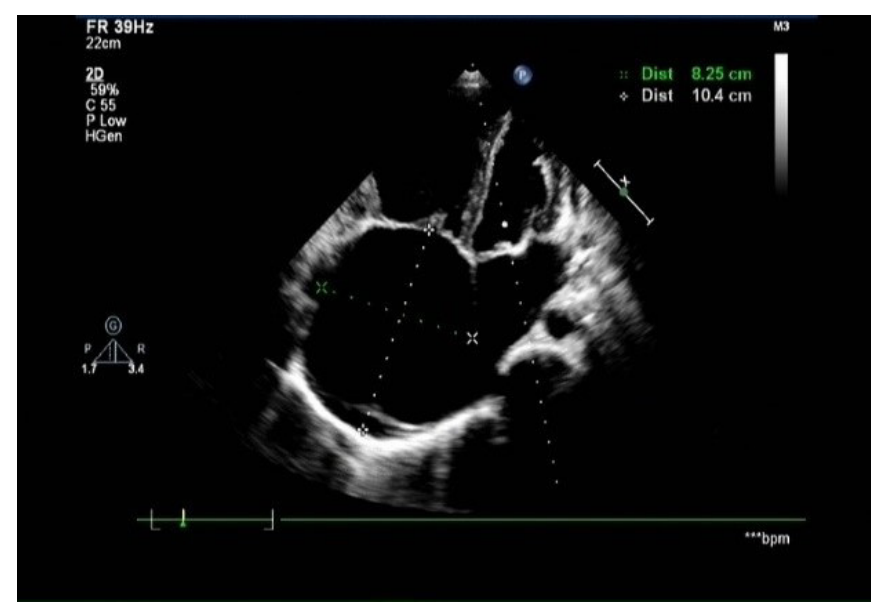

Figure 1. Preoperative echocardiography. A huge RA is visible.

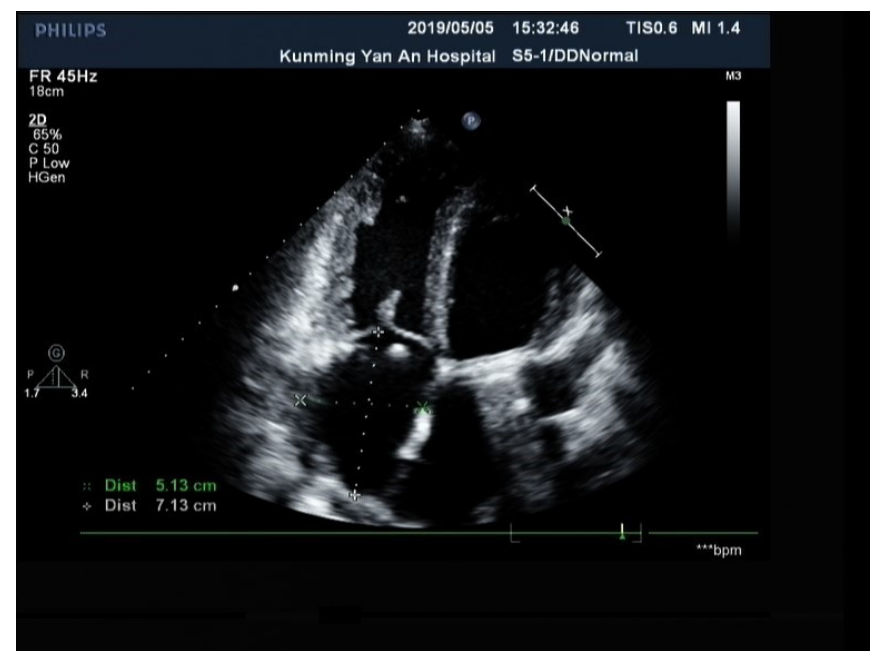

Figure 3. Echocardiography shows a significant reduction in the RA 1 month after surgery.

of LS depend on the balance between ASD and MS. The prognosis is affected by numerous factors, including pulmonary vascular resistance, RV compliance, ASD size and MV stenosis severity, and the occurrence of secondary pulmonary hypertension and congestive heart failure, which are usually associated with poor prognosis [Aminde 2015]. MV stenosis adversely affects ASDs by increasing the left-to-right shunt, thereby leading to RV dilation and tricuspid regurgitation. The left-to-right shunt of the ASD can lead to right heart overload, increased pulmonary blood flow, and pulmonary hypertension [Varsha 2017]. MV stenosis and increased leftto-right shunt result in increased left atrial pressure, which in turn leads to atrial dilation. The expansion of the atrium puts the patient at risk of atrial arrhythmias such as atrial fibrillation [Henry 1976]. In this report, the patient presented with chest tightness and shortness of breath, and clinical examination revealed abdominal distension and hepatomegaly due to increased left-to-right shunt and increased right heart

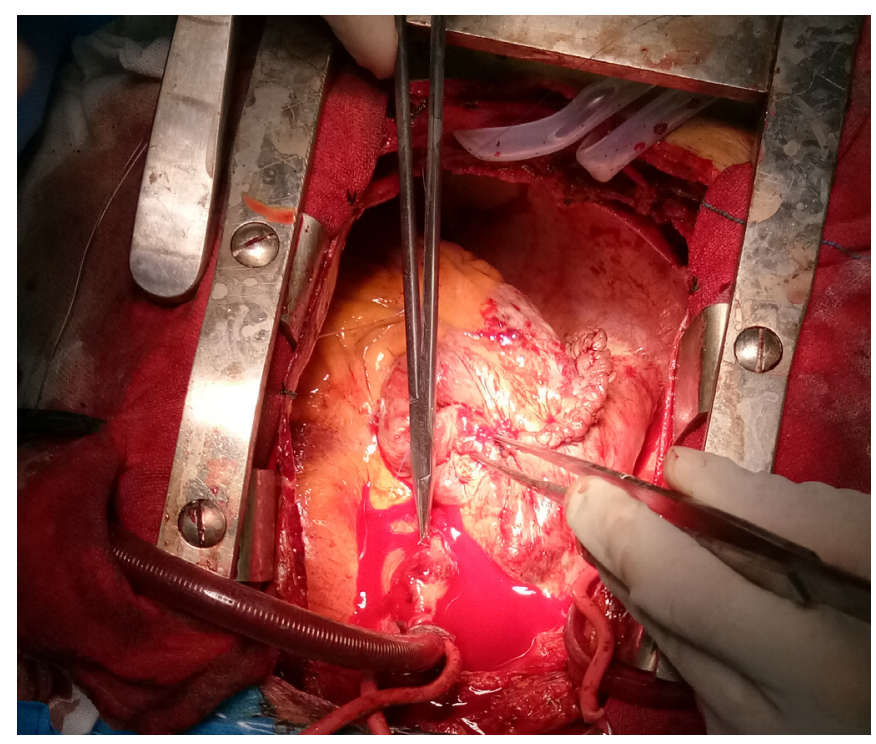

Figure 2. MV replacement under cardiopulmonary bypass, ASD repair, tricuspid annuloplasty, and RA volume reduction.

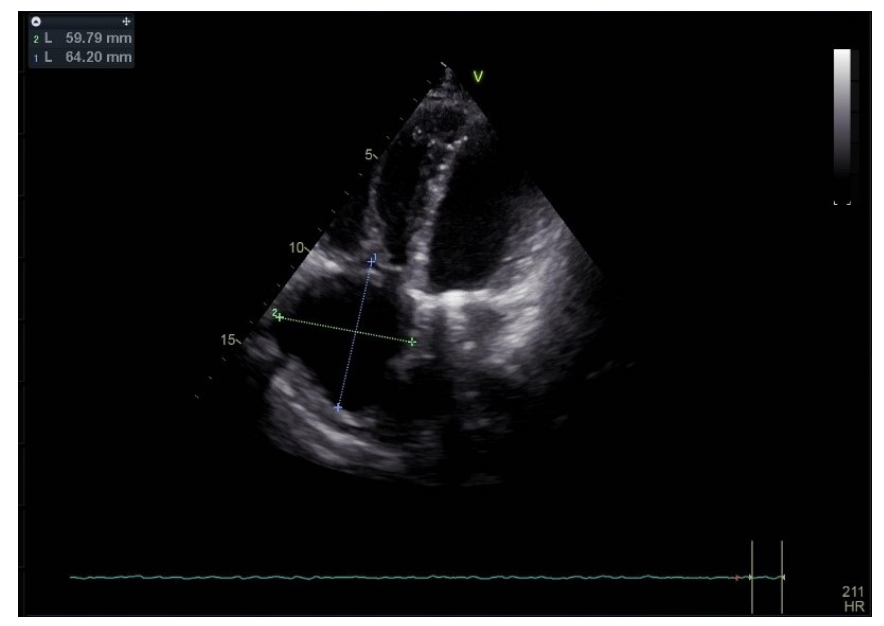

Figure 4. Echocardiography 3 months after surgery.

load, which in turn resulted in increased pulmonary blood flow, decreased cardiac output, pulmonary hypertension, and changes in heart structure.

Echocardiography is the gold standard for diagnosing LS. Given the limitations of 2-dimensional echocardiography, especially the identification of calcification and subvalvular involvement and accurate determination of the area of the MV orifice, 3-dimensional echocardiography should be used to evaluate the MV device before treatment [Tezcan 2014].

Pulmonary vasodilators are recommended for patients with pulmonary hypertension to improve symptoms and prognosis and are widely used to improve patients' exercise capacity and quality of life [Blok 2017]. In addition, preoperative optimization of heart failure medications is crucial to improve surgical outcomes. Surgical treatment of LS mainly includes open heart surgery, MV replacement or repair, and 
atrial septal repair; however, closure of the ASD in patients with severe pulmonary hypertension may result in acute right heart failure. Nonetheless, this risk can be reduced by opening the window on the patch and interventional blocking [Khanna 2014]. Percutaneous balloon mitral valvuloplasty and transcatheter closure of the ASD are less-invasive interventional techniques that are effective alternatives to open heart surgery and avoid its associated complications [Mathur 2018]. In this report, the patient had moderate to severe MV stenosis and mild regurgitation with calcification, severe tricuspid regurgitation, and a huge RA. Hence, we performed open heart surgery. The patient's symptoms improved significantly 1, 3, 6, and 12 months postoperatively (Table 1).

The patient's cardiac function recovered close to normal, and a repeat echocardiogram showed a significant reduction in the RA and RV after surgery (Figure 4). Thus, our report demonstrates the value of surgical treatment in a patient with LS and a huge RA. This report also highlights the clinical utility of echocardiography to facilitate the early diagnosis of LS and related pulmonary complications and guide surgical decision-making; therefore, echocardiography may play a decisive role in the prognosis of patients.

\section{ACKNOWLEDGMENTS}

We thank Dr. Yaxiong Li for helpful discussions and assistance.

\section{REFERENCES}

Alam MM, Khaled MFI. An incidental diagnosis of rheumatic mitral stenosis and secundum atrial septal defect (Lutembacher's syndrome) in a young woman. Case Rep Cardiol 2019;2019:9402987.

Aminde LN, Dzudie A, Takah NF, Ngu KB, Sliwa K, Kengne AP. Current diagnostic and treatment strategies for Lutembacher syndrome: The pivotal role of echocardiography. Cardiovasc Diagn Ther 2015;5:122-132.

Blok IM, van Riel A, van Dijk APJ, Mulder BJM, Bouma BJ. From bosentan to macitentan for pulmonary arterial hypertension and adult congenital heart disease: Further improvement?. Int J Cardiol 2017;227:51-52.

Henry WL, Morganroth J, Pearlman AS, et al. Relation between echocardiographically determined left atrial size and atrial fibrillation. Circulation 1976;53:273-279.

Khanna SN, Paul M, Bhan S, Sharma KK. Surgical correction of Lutembacher's syndrome in a patient with severe pulmonary artery hypertension. J Card Surg 2014;29:569-571.

Mahajan K, Oliver TI. Lutembacher Syndrome. Treasure Island (FL), StatPearls Publishing; 2020.

Mathur R, Sanghvi S, Baroopal A. Percutaneous transcatheter treatment of Lutembacher syndrome. J Assoc Physicians India 2018;66:100-101.

Tezcan M, Isilak Z, Atalay M, Uz O. Echocardiographic assessment of Lutembacher syndrome. Kardiol Pol 2014;72:660.

Varsha AV, George G, Sahajanandan R. Lutembacher syndrome: Dilemma of doing a tricuspid annuloplasty. Ann Card Anaesth 2017;20:456-458. 